\title{
Respiratory Compromise as a New Paradigm for the Care of Vulnerable Hospitalized Patients
}

\author{
Timothy A Morris MD, Peter C Gay MD, Neil R MacIntyre MD FAARC, \\ Dean R Hess PhD RRT FAARC, Sandra K Hanneman PhD RN, James P Lamberti MD, \\ Dennis E Doherty MD, Lydia Chang MD, and Maureen A Seckel APRN
}

\author{
Introduction \\ Definition of Respiratory Compromise \\ Patients At Risk for Respiratory Compromise \\ The Current Challenge of Respiratory Compromise \\ Rapid Response Teams \\ Detection Strategies for Specific Types of Respiratory Compromise \\ Respiratory Compromise Due to Impaired Control of Breathing \\ Respiratory Compromise Due to Impaired Airway Protection \\ Respiratory Compromise Due to Parenchymal Lung Disease \\ Respiratory Compromise Due to Increased Airway Resistance \\ Respiratory Compromise Due to Hydrostatic Pulmonary Edema and Due \\ to Right-Ventricular Failure \\ Manifestations Common to Different Types of Respiratory Compromise \\ Summary and Recommendations
}

\begin{abstract}
Acute respiratory compromise describes a deterioration in respiratory function with a high likelihood of rapid progression to respiratory failure and death. Identifying patients at risk for respiratory compromise coupled with monitoring of patients who have developed respiratory compromise might allow earlier interventions to prevent or mitigate further decompensation. The National Association for the Medical Direction of Respiratory Care (NAMDRC) organized a workshop meeting with representation from many national societies to address the unmet needs of respiratory compromise from a clinical practice perspective. Respiratory compromise may arise de novo or may complicate preexisting lung disease. The group identified distinct subsets of respiratory compromise that present similar opportunities for early detection and useful intervention to prevent respiratory failure. The subtypes were characterized by the pathophysiological mechanisms they had in common: impaired control of breathing, impaired airway protection, parenchymal lung disease, increased airway resistance, hydrostatic pulmonary edema, and right-ventricular failure. Classification of acutely ill respiratory patients into one or more of these categories may help in selecting the screening and monitoring strategies that are most appropriate for the patient's particular pathophysiology. Standardized screening and monitoring practices for patients with similar mechanisms of deterioration may enhance the ability to predict respiratory failure early and prevent its occurrence. Key words: respiratory compromise; respiratory failure; quality improvement. [Respir Care 2017;62(4):497-512. (C) 2017 Daedalus Enterprises]
\end{abstract}




\section{Introduction}

This monograph introduces an approach to the common and very serious clinical problem of respiratory compromise encountered in hospitalized patients. Respiratory compromise is a deterioration in respiratory function that poses a high risk of life-threatening respiratory failure. Various authors have used the phrase "respiratory compromise" to describe intensities of respiratory dysfunction ranging from a chronic state of respiratory insufficiency ${ }^{1,2}$ to conditions that require emergency resuscitation with mechanical ventilation. $^{3}$ This work, however, focuses on hospitalized patients who are at high risk for respiratory failure or death but for whom such devastating complications are poten-

Dr Morris is affiliated with the Division of Pulmonary and Critical Care Medicine. University of California, San Diego, California. Dr Gay is affiliated with Pulmonary and Critical Care Medicine, Mayo Clinic, Rochester, Minnesota. Dr MacIntyre is affiliated with the Division of Pulmonary, Allergy, and Critical Care Medicine. Duke University School of Medicine, Durham, North Carolina. Dr Hess is affiliated with the Department of Respiratory Care, Massachusetts General Hospital and Department of Anesthesia, Harvard Medical School, Boston, Massachusetts. Dr Hanneman is affiliated with the Department of Acute and Continuing Care, School of Nursing, University of Texas Health Science Center at Houston, Houston, Texas. Dr Lamberti is affiliated with the Department of Medicine, Inova Fairfax Hospital, Annandale, Virginia. Dr Doherty is affiliated with the Division of Pulmonary, Critical Care, and Sleep Medicine, University of Kentucky and the Lexington Veterans Administration Medical Center, Lexington, Kentucky. Dr Chang is affiliated with the Division of Pulmonary Diseases and Critical Care Medicine, University of North Carolina, Chapel Hill, North Carolina. Ms Seckel is affiliated with the Medical Intensive Care Unit, Christiana Care Health Services, Wilmington, Delaware.

The invitational workshop on respiratory compromise was funded by the National Association for Medical Direction of Respiratory Care and by unrestricted educational grants from Medtronic, Philips/Respironics, Masimo, Hill-Rom, Maquet, Genentech, and Welch Allyn. The content of this monograph reflects the discussion of the workshop participants and not that of the workshop sponsors. The views expressed are those of the individual participants and do not constitute an official statement from the societies represented at the meeting. Dr Morris has disclosed relationships with Bayer, Philips, and Medtronics; Dr Gay has disclosed a relationship with Fisher Paykel; Dr MacIntyre has disclosed a relationship with Medtronics; Dr Hess has disclosed relationships with Philips Respironics, Medtronic, Bayer, Ventec, Jones and Bartlett, McGraw-Hill, UpToDate, and the American Board of Internal Medicine; Dr Lamberti has disclosed relationships with Janssen, GlaxoSmithKline, and Boehringer Ingelheim; and Dr Doherty has disclosed relationships with Astra Zeneca and Boehringer Ingelheim. The other authors have disclosed no conflicts of interest.

Editor in Chief Dean Hess was blinded to the peer review of this paper, which was managed by Deputy Editor Richard Branson.

Correspondence: Timothy A Morris MD, Division of Pulmonary and Critical Care Medicine. University of California, 200 West Arbor Drive, San Diego, CA 92103-8378. E-mail: t1morris@ucsd.edu.

DOI: $10.4187 /$ respcare.05021 tially avoidable. Identifying patients in respiratory compromise and those in whom respiratory compromise is worsening is a critical component of in-patient hospital care. Only if this is effectively done can appropriate interventions be instituted to avoid catastrophic events.

This monograph is the result of a project that emerged from discussions among a group of interested pulmonary specialist members of the National Association for the Medical Direction of Respiratory Care (NAMDRC) that led to the organization of a sentinel workshop meeting in 2015 with representation from many national societies to address respiratory compromise from a clinical practice perspective. The purpose of the workshop was to establish the groundwork for further discussion and research focused on identifying respiratory compromise early and enacting interventions promptly to reverse the compromise and thereby prevent respiratory failure. The workshop participants included physicians, nurses, respiratory therapists, and industry partners committed to the diagnosis and management of patients at risk of or already faced with respiratory compromise. However, only the clinicians at the workshop were members of the writing committee that authored this manuscript, whereas the industry sponsors identified were permitted only to ask questions and interact informally with the participants at the conference.

The goals of the workshop were to: (1) define respiratory compromise and its determinants, (2) identify types of patients most likely to experience respiratory compromise during hospitalization, and (3) recommend monitoring strategies to prevent and to detect the occurrence and severity of respiratory compromise early in its progression. The goals were addressed after a review of pathologic and pathophysiologic mechanisms that lead to respiratory compromise. An overview of respiratory compromise and the thoughts and recommendations of the invitational workshop participants are presented.

This monograph presents the overall framework of the conference and begins with a general definition of respiratory compromise. A description follows of how the participants chose to categorize subsets of patients with a clarification of some unique features. The many ways these patients are or become vulnerable and eventually reveal signs and symptoms of respiratory compromise are identified and discussed. The current challenges and an outline of detection strategies for patients with respiratory compromise are initially offered. An in-depth thesis of each subset of patients is then provided with the primary physiologic mechanisms and derangements for each explained, followed by the specific most important parameters to identify and monitor in the individual subsets.

Our ultimate hope is that this report will stimulate interested parties to develop proposals that result in further research. Only then can we as clinicians and scientists produce meaningful protocols to reduce the incidence of 


\section{Respiratory Compromise Paradigm for the Care of Vulnerable Patients}

more severe episodes of respiratory compromise and ultimately improve patient care.

\section{Definition of Respiratory Compromise}

As noted in the introduction, respiratory compromise describes a deterioration in respiratory function in which there is a high likelihood of decompensation into respiratory failure or death but for which timely specific interventions (enhanced monitoring or therapies) might prevent or mitigate decompensation. For example, timely antibiotic therapy decreases mortality in patients hospitalized with moderately to highly severe community-acquired pneumonia, ${ }^{4}$ and early noninvasive ventilation reduces mortality in those hospitalized with severe COPD. ${ }^{5}$ Although respiratory compromise can be a chronic stable condition for many years, in our discussions here, we focus on respiratory compromise in the acute environment, where patients are at risk for deterioration of respiratory function, potentially leading to respiratory failure and death. Ideally, worsening respiratory compromise would be amenable to specific interventions (enhanced monitoring or therapies) that would prevent or mitigate further decompensation. Patients fall, at any particular time point, on a continuum of illness severity and risk. Respiratory compromise suggests a change in respiratory status that entails a likelihood of increased morbidity or mortality if deterioration is not prevented or mitigated.

Respiratory failure occurs when patients have physiologically deteriorated to the point at which advanced life support interventions are unequivocally necessary for recovery. Respiratory compromise can de-escalate as well as escalate, either spontaneously or in response to intervention(s). Thus, efficacious and efficient monitoring is essential to determine where the patient with respiratory compromise is on the continuum of risk for respiratory failure. Introduction of the term respiratory compromise is intended to focus attention on the vulnerable population of patients for whom early intervention might have the best potential for avoiding respiratory failure. In addition to improving outcomes, early recognition of respiratory compromise might allow more efficient resource utilization and more appropriate performance evaluation of health-care systems. ${ }^{6-9}$

\section{Patients at Risk for Respiratory Compromise}

Patients in acute care hospitals, particularly those with respiratory conditions, are at risk for developing respiratory compromise. Respiratory failure requiring emergency mechanical ventilation occurs in $>44,000$ patients per year in the United States. ${ }^{3}$ In postoperative patients in the United States, the National Surgical Quality Improvement Pro- gram reports that $1.03 \%$ of all surgical patients require an unplanned intubation postoperatively. ${ }^{10}$

Patients hospitalized with respiratory illnesses have higher death rates than those hospitalized for any other common condition. ${ }^{11}$ The development of in-hospital respiratory failure is associated with a mortality of nearly $40 \% .^{3}$ The rates of in-hospital deaths in patients with respiratory failure are more than twice as high as for myocardial infarction and several times higher than for cancer, stroke, congestive heart failure, and renal failure. ${ }^{11}$ The high mortality associated with respiratory failure highlights the rationale for recognition of respiratory compromise and intervention before the development of respiratory failure.

The likelihood of suffering from respiratory failure and death is variable and dynamic. Patients admitted to hospitals with preexisting respiratory conditions have relatively high mortality rates. ${ }^{12,13}$ Patients admitted with acute pneumonia have significant mortality rates, ${ }^{14,15}$ and those admitted with aspiration have even higher rates of death. ${ }^{16}$ Death may not be due directly to the lung infection, since $>1$ in 4 patients with community-acquired pneumonia develop heart failure, arrhythmias, or myocardial infarction. ${ }^{17}$ Higher mortality rates may occur with health care-associated pneumonia, even when considering infections without antibiotic resistance. ${ }^{18}$ Worsening respiratory compromise is associated with substantial increases in mortality for patients with viral respiratory infections, ${ }^{19}$ neutropenia, ${ }^{20}$ and hematological malignancies. ${ }^{21}$ Acute respiratory failure from either acute lung injury or cardiogenic pulmonary edema also is associated with a high risk of death in the months after hospitalization. ${ }^{22}$

Although respiratory compromise may develop de novo during hospitalization in patients without preexisting lung disease, in other patients, it develops as a complication of chronic respiratory diseases, such as COPD. Patients hospitalized with severe exacerbations of COPD have particularly high mortality rates. ${ }^{23}$ The tools for identifying, monitoring, and intervening in respiratory compromise in the setting of preexisting disease subsets may be different from the tools used in de novo respiratory compromise. For example, the likelihood of death during admission for COPD exacerbation reflects the underlying disease severities $^{24,25}$ as well as the presence of coexisting cardiovascular diseases. ${ }^{25}$ Conversely, COPD is a common and dangerous comorbidity in patients with chronic heart failure. ${ }^{26}$

A variety of non-respiratory conditions also place patients at risk for respiratory failure and death. Procedural sedation and other anesthetic approaches entail suppression of ventilation and reduced airway protection to some degree and, therefore, can cause respiratory compromise during the perioperative period. Postoperative patients are susceptible to respiratory failure from opiate-induced respiratory depression and immobility-induced pulmonary 


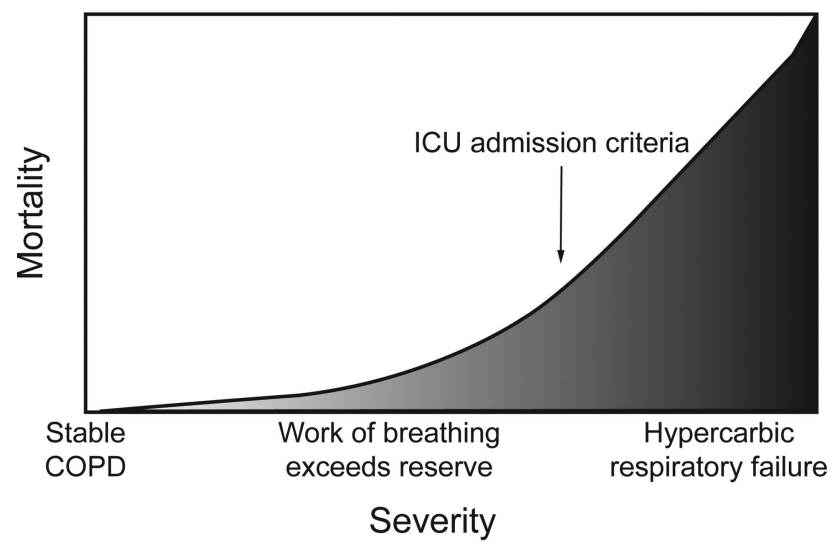

Fig. 1. Severity in patients with respiratory compromise. COPD is used as an example of the effect of worsening disease severity on mortality. As the manifestations of the disease become progressively more severe, the mortality continuously increases. ICU admission often occurs after the condition has deteriorated to the extent that mechanical ventilation is necessary. ${ }^{27}$

embolus or atelectasis. Neurological impairment likewise increases the risk for respiratory failure from reduced mobility and/or altered ventilatory control mechanisms. Patients who do not have respiratory conditions upon admission to an acute care hospital can move from no risk to respiratory compromise due to a newly developed condition, incidental procedures, or treatment.

\section{The Current Challenge of Respiratory Compromise}

Integral to the concept of respiratory compromise is the likelihood that alterations in a patient's normal respiratory condition or in one's stable chronic respiratory condition will lead to morbidity or mortality, which depends on both the severity of the acute illness and on its associated risks. Although they are related, severity and risk may lead to different strategies for surveillance, diagnosis, and treatment. In this discussion, severity implies the level of deterioration that develops during the continuum of a disease process. The progression of the natural history of the disease leads to adverse outcome(s) (eg, the development of hypercarbic respiratory failure during a COPD exacerbation) (Fig. 1). Risk refers to the probability of a new problem that is not currently present but to which patients' conditions make them vulnerable (eg, aspiration pneumonia in a patient treated with high-dose analgesics or sedatives) (Fig. 2).

Recognition of respiratory compromise on the basis of both severity and risk is a critical step in the development of preventive strategies and surveillance systems to identify respiratory compromise changes early and thus help to prevent respiratory failure and death. Increased attention, observation, and therapeutics substantially improve the probability of survival in deteriorating patients ${ }^{28}$; delay of

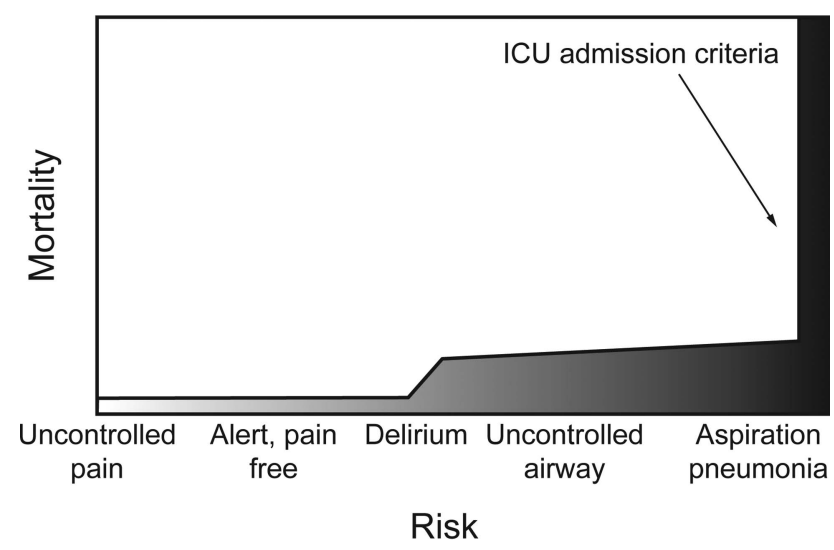

Fig. 2. Risk in patients with respiratory compromise. Analgesiainduced loss of airway control is used as an example of the effect of increasing disease risk on mortality. As the condition worsens, specific events (aspiration in this example) may occur that incrementally increase mortality. ICU admission often occurs after the catastrophic event has occurred. ${ }^{27}$

such interventions for patients developing acute respiratory failure increases the chances of death. ${ }^{29}$ On the other hand, most interventions (eg, aggressive respiratory secretion clearance ${ }^{30}$ ) require additional resources that are not feasible to provide to the majority of in-patients. It may not be straightforward to determine which patients are in sufficient jeopardy to warrant resource-intensive interventions.

There are examples of clinically validated data to help recognize respiratory compromise on the basis of the severity of the underlying conditions and the risk of deterioration. Standard clinical parameters, such as vital signs and basic laboratory tests, are of course useful. ${ }^{31-33} \mathrm{In}$ addition, risk adjustment models have been validated for predicting outcome across a broad range of patients with and without preexisting respiratory illnesses. ${ }^{34-40}$ Because of the especially high risk inherent to worsening of acute respiratory compromise, data relevant to gas exchange and the need for respiratory support are particularly applicable. ${ }^{41}$

Thorough assessment of severity and risk may require consideration of several different models. Respiratory compromise may affect heterogeneous categories of patients, with or without preexisting respiratory diseases and conditions. Data applicable to one condition may not predict outcomes in a different one. For example, numerous models have been clinically validated to gauge the severity of community-acquired pneumonia. ${ }^{42-48}$ However, the criteria recommended by the Infectious Disease Society of America and the American Thoracic Society to estimate the severity of community-acquired pneumonia ${ }^{49}$ are much less accurate when applied to community-acquired pneumonia that is related to aspiration. ${ }^{16}$ The pneumonia models differ from the clinically validated models applicable 


\section{Respiratory Compromise Paradigm for the Care of Vulnerable Patients}

to exacerbations of COPD, ${ }^{50-53}$ which, in turn, are dissimilar from the validated models to predict outcome from acute pulmonary embolism ${ }^{54,55}$ or hemoptysis. ${ }^{56}$ Respiratory problems of different etiologies may require different models to predict the risk of death and determine which patients are at sufficient risk to warrant intervention.

The challenge at hand is the need for early recognition of patients who move along the continuum of severity and/or risk into a state of respiratory compromise. If clinicians fail to recognize a change in status early, patients will probably deteriorate and perhaps experience respiratory failure. The time span of progression can be quite variable, from minutes to days. Current processes that are utilized to recognize changes in patient status are visual monitoring, or intermittent (spot) checks, by clinicians and continuous monitoring by electronic devices. Neither approach will prevent or mitigate worsening respiratory compromise in every case, but either (or both) can help in many cases. Staffing ratios preclude continuous visual monitoring at the bedside in most areas of the hospital. A patient can deteriorate rapidly in an interval between frequent spot checks (eg, a patient can aspirate moments after the clinician leaves the bedside). Although electronic devices monitor continuously and emit warning signals when preset parameters are exceeded, most devices in clinical use today monitor only a single or very few parameters. A pulse oximeter, for example, will not detect a rising carbon dioxide level in an apneic patient on supplemental oxygen therapy until oxygenation or perfusion has been seriously compromised. On the other hand, if alarms are too frequent, alarm fatigue will set in, and signals will be ignored. Thus, a current challenge is to optimize approaches to prevention and early detection of respiratory compromise that benefit patients effectively and efficiently.

\section{Rapid Response Teams}

Rapid response teams were created to facilitate the recognition and treatment of patients at the highest risk of deterioration. ${ }^{57}$ The rapid response team strategy plays a significant role in the rescue of respiratory patients, since a large proportion of rapid response team interventions are respiratory in nature. ${ }^{58}$ The effect of rapid response teams is controversial; earlier studies were disappointing, 59,60 whereas later studies showed a beneficial effect on mortality or other important outcomes. ${ }^{58}$ The inconsistencies among reports may be due to the "striking degree of variation" observed in how care is delivered among systems. ${ }^{58}$ Whatever the current benefits are, there is an opportunity to update the triggers for rapid response team activation from the relatively simple clinical parameters commonly used (breathing frequency, heart rate, blood pressure, mental state, and the nebulous "staff worried" criterion) $)^{57}$ to ones that reflect the stratification of severities and risks characteristic of respiratory compromise in specific patient populations.

\section{Detection Strategies for Specific Types of Respiratory Compromise}

Effective prevention, early detection, and intervention for respiratory compromise may be guided by an understanding of the varied mechanisms by which respiratory homeostasis is maintained and by identifying the most common mechanisms by which it deteriorates. Sophisticated algorithms that monitor clinically validated data reflecting those mechanisms might improve the ability to intervene early in patients with deteriorating respiratory conditions. Individual algorithms could then be tailored toward specific patient groups who have specific pathophysiologic patterns and trajectories in common. We propose that monitoring and interventional strategies focus on the patterns of deterioration that are characteristic of the various types of respiratory compromise that we describe.

Respiratory homeostasis depends on the complex interplay between ventilatory patterns, lung volume, ventilation/perfusion $(\dot{V} / \dot{Q})$ matching, and right-ventricular function. Respiratory compromise occurs as a result of dysfunction in one or more homeostatic mechanisms and the inability of others to compensate adequately. Although respiratory failure is caused by a heterogeneous group of processes, there are subsets of patients who manifest similar patterns of deterioration (Table 1). Patients within those subsets might benefit from similar monitoring approaches and interventions.

\section{Respiratory Compromise Due to Impaired Control of Breathing}

\section{Physiological Derangement}

The normal ventilatory pattern arises as the brainstem processes various inputs that affect its pacemaker function. Neural inputs include conscious and unconscious stimuli, stress responses, and state of alertness. The brainstem also responds to mechanical input from lung stretch and irritant receptors. The chemical properties of the blood affected by gas exchange (ie, $\mathrm{P}_{\mathrm{aO}}, \mathrm{P}_{\mathrm{CO}_{2}}$, and $\mathrm{pH}$ ) also have powerful effects on breathing frequency and depth. The brainstem output occurs through the phrenic nerves to the diaphragm as well as through nerves that control other thoracic respiratory muscles. Through intricate control of ventilatory rate, tidal volume, flow patterns, and the resulting inspiration and exhalation times, the respiratory system maintains adequate $\mathrm{P}_{\mathrm{O}_{2}}$ and $\mathrm{pH}$ while minimizing the metabolic work performed.

Respiratory compromise may occur from impaired ability to control ventilation in patients with brainstem 


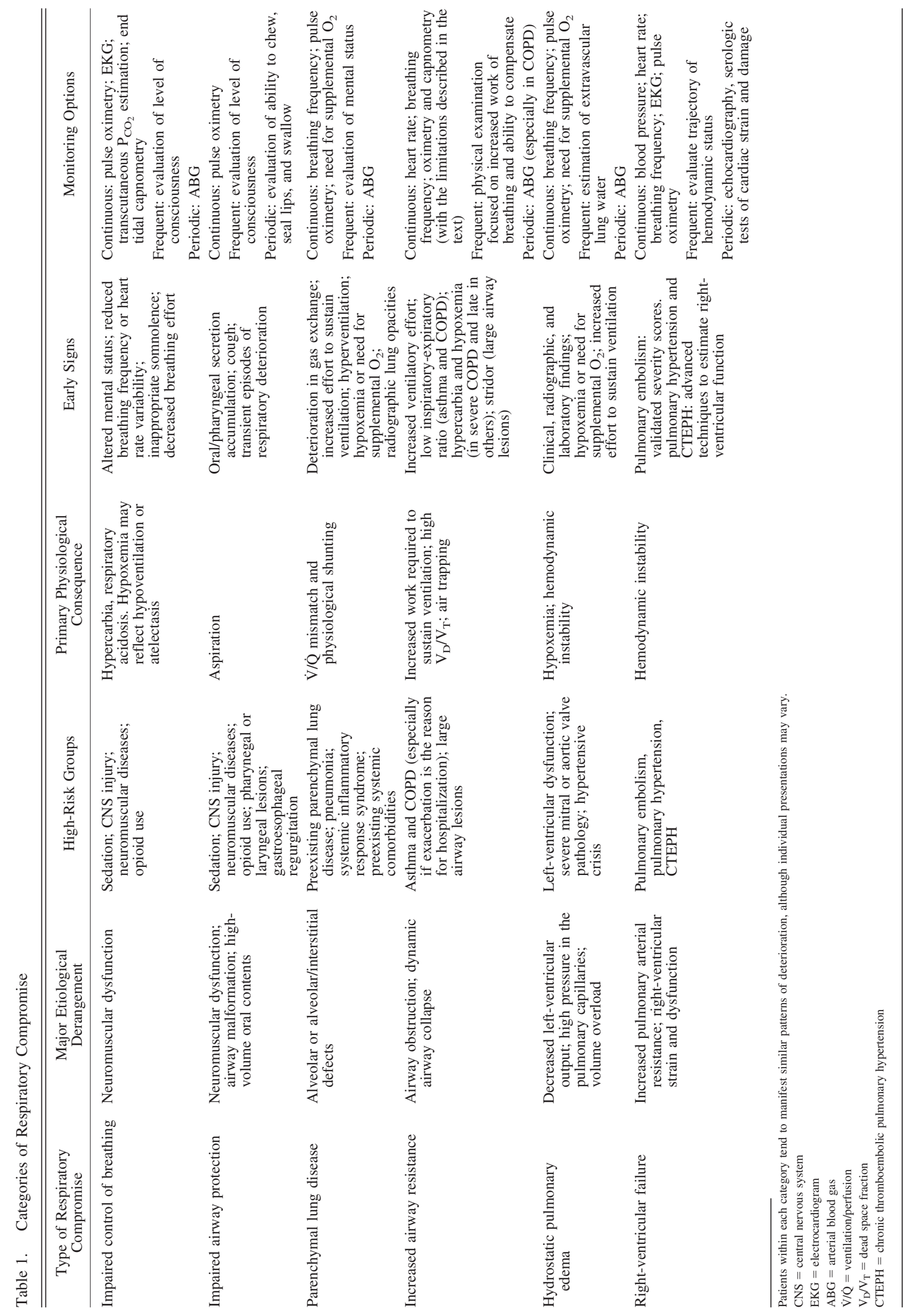


dysfunction due to central nervous system injury, pharmacologic/toxic depressants, metabolic disorders, and sleep-associated breathing disorders. Patients with neuromuscular weakness due to disease, toxins, or injuries also are unable to optimally control ventilation. In patients with respiratory compromise due to impaired control of breathing, hypoventilation, erratic breathing patterns, or both may reduce alveolar ventilation $\left(\dot{\mathrm{V}}_{\mathrm{A}}\right)$. Hypercarbia and acidosis occur as a direct result of the fall in $\dot{V}_{\mathrm{A}}$. Blood deoxygenation occurs as hypoventilation worsens, although supplemental oxygen may prevent hypoxemia and hinder detection of the problem until hypoventilation is severe.

Apart from hypoventilation itself, conditions associated with respiratory compromise due to impaired control of breathing may be complicated by direct effects on the lung itself. For example, immobility and loss of muscle tone encourage atelectasis. Body malpositioning may also alter lung perfusion patterns, causing $\mathrm{V} / \mathrm{Q}$ mismatching and hypoxemia.

Severe sleep-disordered breathing is a variation of respiratory compromise due to impaired control of breathing that may warrant special monitoring and therapeutic considerations. The apneas and hypopneas resulting from sleeprelated inhibition of the central drive to breathe, development of upper-airway obstruction, or a combination of the two may lead to reduced $\dot{\mathrm{V}}_{\mathrm{A}}$, hypoxemia, and respiratory acidosis. If the arousal reflex fails further, either as a result of the disorder itself or because of other illnesses or medications, then hypoxemia and respiratory acidosis may progress to respiratory failure and even cardiopulmonary collapse.

\section{Identification of Patients in Respiratory Compromise Due to Impaired Control of Breathing}

Patients who are particularly likely to develop respiratory compromise due to impaired control of breathing include those with postoperative sedation, procedural sedation, central nervous system injury, neuromuscular disease, or sleep apnea (central or obstructive) and those given opioids or related respiratory suppressant drugs. Respiratory compromise due to impaired control of breathing is characterized by hypoventilation with reduced breathing frequency and tidal volume, which results in hypercarbia and hypoxemia. It may manifest signs of altered mental status or behavior changes, reduction in the variability of the breathing frequency or the heart rate, or changes in blood pressure (up or down). Although somewhat difficult to quantify, inappropriate somnolence and markedly decreased breathing effort may represent early signs of respiratory compromise, so patients at risk for respiratory compromise due to impaired control of breathing should undergo careful physical examination at regular intervals.
Respiratory compromise in patients at risk for hypoventilation may be identified most easily by the clinical features of $\mathrm{CO}_{2}$ narcosis. Unexplained or new, even subtle mental status change should prompt clinicians to consider an arterial blood gas measurement. Waiting for more extreme hypersomnolence is likely to next be met with unarousability and potential need for aggressive ventilatory intervention, including immediate intubation. Because hypoventilation may sometimes be misdiagnosed as COPD, ${ }^{61,62}$ the possibility of respiratory compromise due to impaired control of breathing should be considered in patients with hypercarbia but without overt signs of airway obstruction. The combination of hypoxemia and a body mass index $>35 \mathrm{~kg} / \mathrm{m}^{2}$ is suggestive of obesity hypoventilation. ${ }^{63} \mathrm{Co}-$ morbidities such as diabetes, metabolic syndrome, nonalcoholic steatohepatitis, cardiac dysfunction, and pulmonary hypertension are especially prominent among those at highest risk for respiratory failure. ${ }^{62}$

\section{Monitoring Parameters Suggested After Identification of Respiratory Compromise}

Strategies for monitoring patients with respiratory compromise due to impaired control of breathing should ideally include continuous and accurate measurement of gas exchange. Monitoring of blood oxygenation is fairly routine; however, changes in oxygenation are often the fairly abrupt end sequelae of compromised control of breathing. Other available monitoring options appropriate for this subset of respiratory compromise include continuous measurement of blood pressure, electrocardiogram, transcutaneous $\mathrm{P}_{\mathrm{CO}_{2}}$ estimation, and end-tidal capnometry. However, additional tools may need to be developed for an earlier detection of respiratory compromise. Air-flow measurement by a thermistor may monitor the depth and frequency of breathing. Actigraphy may provide an indication of a patient's general activity as a surrogate for the level of consciousness. Periodic arterial blood gas measurements, although not continuous, will provide unequivocal evidence of hypercarbia and hypoxemia. Clinical scales to measure consciousness, sedation, delirium, pain, and risk for sleep apnea may detect decreases in central ventilatory drive.

\section{Respiratory Compromise Due to Impaired Airway Protection}

\section{Physiological Derangement}

Even in the absence of overt hypoventilation, patients with respiratory compromise due to impaired control of breathing are in particular danger if poor airway protection leads to aspiration. Aspiration pneumonia carries a high risk of death, and its prevention warrants special consid- 
eration in respiratory compromise due to impaired control of breathing, separate from the management of gas exchange impairment. Aspiration pneumonia incurs its own separate mechanisms that lead to hypoxemia, acidosis, and mechanical loading; once aspiration occurs, the patient is more appropriately considered to be in the category of respiratory compromise from parenchymal lung disease, which we describe below.

\section{Identification of Patients in Respiratory Compromise Due to Impaired Airway Protection}

Patients with neurological, gastrointestinal, or upperairway anatomical disorders that affect the ability to properly swallow and effectively cough may be in respiratory compromise due to impaired control of the upper airway. These disorders are most likely to affect the ability to properly swallow and effectively cough. Although there is overlap in manifestations of respiratory compromise in patients with neuromuscular depression and those with pulmonary aspiration, the latter is associated with tachypnea, increased breathing effort, and hypocarbia as the parenchymal insult dominates.

In patients with neurologic dysfunction, respiratory compromise from inability to control the airway may be initially manifested as dysphagia, which is associated with specified, localized cerebrovascular accidents. Deep cerebral infarcts, especially in the primary somatosensory, motor, motor supplementary, and orbitofrontal regions, are predictive of dysphagia, as are infarcts within the caudate, putamen, and basal ganglia. ${ }^{64}$ Awareness of stroke incidence in these anatomical locations may identify those individuals at risk and help identify those who would benefit from additional monitoring and intervention. Dementia and Parkinson's disease are also risk factors for aspiration pneumonia because of their neuromuscular sequelae. ${ }^{65}$ Other neurologic disorders, such as myasthenia gravis, multiple sclerosis, and amyotrophic lateral sclerosis, predispose to aspiration and subsequently aspiration pneumonitis because of a significant reduction in respiratory muscle compliance and overall mobility. Dehydration is an indicator of poor oral intake and impaired feeding mechanisms, which may predispose this population to aspiration. ${ }^{65}$

In addition to focal neurologic and neuromuscular dysfunctions, alterations in consciousness from medication use and drug abuse increase the risk of aspiration. For example, escalating doses of antipsychotic medications increase the risk of swallowing difficulty. ${ }^{64}$ Chronic opioid dependence may also result in delayed gastric emptying and a higher risk of aspirating residual gastric contents. ${ }^{66}$ Alcoholism, seizures, anesthesia, and head trauma provoke an altered level of consciousness and serve as additional risk factors for aspiration.
Respiratory compromise from inability to control the airway may occur because of gastrointestinal risk factors, such as gastroesophageal reflux disease. Use of acid suppressants enhances the risk for aspiration pneumonia in the event of aspiration, since these medications increase bacterial load by reducing the acidity of the stomach. Respiratory compromise from inability to control the airway may complicate radiation treatment to the head and neck. Radiation-induced tissue damage may cause loss of sensation in the larynx accompanied with failed epiglottic inversion and poor laryngeal elevation with failed clearance of aspirate. ${ }^{66}$ Other disorders of the esophagus and gastrointestinal tract (eg, tumors, strictures, fistulae, achalasia, and obstruction) predispose individuals to aspiration. Additional gastrointestinal disorders include vomiting, obstruction, ascites, gastroparesis, and ileus.

Respiratory compromise in patients following aspiration may be identified by findings associated with either aspiration pneumonitis or aspiration pneumonia. Aspiration pneumonitis, a chemical injury with subsequent inflammatory response that occurs after aspiration of gastric contents, presents clinically within hours of aspiration with coughing, wheezing, dyspnea, tachypnea, leukocytosis, hypoxemia, and perhaps bloody or frothy secretions. ${ }^{67}$ Aspiration pneumonia from inhalation of oropharyngeal contents occurs in $5-15 \%$ of patients diagnosed with pneumonia and carries an increased mortality risk of $15-21 \% .16,68,69$ Respiratory compromise from aspiration pneumonia presents as tachypnea, cough, fever or hypothermia, tachycardia, hypocarbia, and hypoxemia. Changes in breath sounds are dependent on patient position at the time of aspiration: If recumbent, decreased breath sounds and/or rales may be heard in the posterior upper lobes and apical segments of the lower lobes; if semi-recumbent or upright, altered auscultation findings are likely to be heard in the basal segments of the lower lobes. ${ }^{67}$

\section{Monitoring Parameters Suggested After Identification of Respiratory Compromise}

Monitoring of patients in respiratory compromise due to impaired control of the upper airway may include repeated evaluations of the level of consciousness and the ability to chew, seal the lips, and swallow. ${ }^{70}$ Patients with compromised control of breathing may require regular assessment of neurologic function with intervention when the patient crosses the threshold at which risk for aspiration and loss of airway control becomes unacceptably high. The commonly utilized threshold value of the Glasgow coma scale of 8 is a fairly blunt instrument and does not account for additional patient factors such as volume and tenacity of airway secretions. In addition, transient episodes of respiratory status deterioration, even if they are brief and selflimited, may be warning signs of subsequent respiratory 
failure. Finally, observers such as family members may provide important information about changes in consciousness and ventilatory drive in patients with respiratory compromise due to impaired control of breathing.

\section{Respiratory Compromise Due to Parenchymal Lung Disease}

\section{Physiological Derangement}

The volume of the lungs depends on both the activity of the ventilatory muscles (or of mechanical support devices) and mechanical factors determining functional residual capacity (FRC) (ie, volume of the lungs in the resting state). Balance between the pressure/volume relationship (compliance) of the chest wall and the same relationship within the lung determines the volume of the FRC. Various pathological conditions, such as COPD, ARDS, and lung fibrosis impose characteristic changes on lung compliance that affect FRC.

Gas exchange depends on $\dot{V}_{\mathrm{A}}$, which is determined by the total amount of ventilation $\left(\dot{\mathrm{V}}_{\mathrm{E}}\right)$ minus the ventilation that occurs without gas exchange (ie, dead-space ventilation $\left.\left[\dot{\mathrm{V}}_{\mathrm{D}}\right]\right)$. Whereas the conducting airways normally account for about $2 \mathrm{~mL} / \mathrm{kg}$ of "anatomic" $\dot{\mathrm{V}}_{\mathrm{D}}$, lung pathology can substantially increase $\dot{V}_{D}$. Gas exchange also depends on $\dot{V} / \dot{Q}$ matching and diffusion across alveolarcapillary membranes.

Parenchymal lung disease may cause respiratory compromise through a number of related mechanisms. In respiratory compromise due to parenchymal lung disease, lung compliance commonly decreases, which causes a fall in the FRC. High metabolic work is required to overcome the increased elastic recoil of the lung and maintain ventilation. Imbalance between the work required to breathe and the patient's capacity for metabolic work is manifested by rapid, shallow breathing. The disordered breathing pattern increases the $\dot{\mathrm{V}}_{\mathrm{D}} / \dot{\mathrm{V}}_{\mathrm{E}}$ and decreases $\dot{\mathrm{V}}_{\mathrm{E}}$. The combination of the two may compromise $\dot{\mathrm{V}}_{\mathrm{A}}$ to cause hypoxemia and respiratory acidosis. However, when parenchymal lung disease causes respiratory compromise, the predominant defect is commonly the gas exchange impairment from the parenchymal disease itself. Alveolar inflammation, infection, edema, and alveolar collapse cause profound $\dot{V} / \dot{Q}$ mismatch and physiological shunting. In fact, during respiratory compromise induced by parenchymal lung disease, compensatory hyperventilation (despite the metabolic cost) may occur early and maintain blood oxygenation temporarily, especially when supplemental oxygen is supplied. Maintenance of blood oxygenation in the early stages of respiratory compromise due to parenchymal lung disease may mask the increasing alveolar-arterial oxygen gradients that portend impending respiratory failure.
Increased pulmonary vascular resistance due to alveolar hypoxemia may complicate respiratory compromise due to parenchymal lung disease. Right-ventricular strain and dilatation can decrease cardiac output. As a result, both $\mathrm{V} / \mathrm{Q}$ matching and systemic oxygen delivery may be further impaired.

\section{Identification of Patients in Respiratory Compromise Due to Parenchymal Lung Disease}

In addition to patients with preexisting parenchymal lung disease, patients likely to develop respiratory compromise include patients with pneumonia and with other infections associated with the systemic inflammatory response syndrome. Preexisting comorbidities, such as diabetes, stroke, heart failure, and immune compromised states, increase the risk of respiratory compromise due to parenchymal lung disease. In the appropriate populations, respiratory compromise due to parenchymal lung disease may be recognized by deterioration in gas exchange or by increases in the effort required to sustain ventilation. In the presence of respiratory deterioration, increases in radiographic lung opacity confirm respiratory compromise due to parenchymal lung disease.

Respiratory compromise in patients with parenchymal lung disease may be identified by the development of physiologic aberrations, such as hypoxemia, needing oxygen supplementation, and tachypnea. There are fairly well defined criteria for the identification of compromised patients with acute parenchymal disease. For example, the lung injury prediction score can identify compromised patients at risk for the development of ARDS. ${ }^{71}$ The score, an aggregate measure of predisposing conditions, such as sepsis and shock, with risk modifiers, such as alcohol, smoking, hypoalbuminemia, oxygen supplementation $(>0.35)$, and tachypnea ( $>30$ breaths/min), effectively discriminates between high- and low-risk patients. Acute respiratory decline in patients with chronic parenchymal lung disease is characterized by worsening hypoxemia and dyspnea, often accompanied by a cough. A majority of patients with fibrotic lung disease hospitalized with these findings are likely to be experiencing an exacerbation of their underlying lung disease. ${ }^{72-75}$ These patients should be recognized early because they have an overall high hospital mortality that warrants timely and accurate prognostic assessment as well as close monitoring for the development of respiratory failure. ${ }^{73,74}$

Once respiratory failure requiring noninvasive ventilation or mechanical ventilation occurs, short-term mortality becomes even higher. ${ }^{76}$ Other factors associated with increased mortality include male sex, increased age, precapillary pulmonary hypertension, and right-heart failure. .4,77 $^{-7}$ Specific underlying diagnoses, such as idiopathic pulmonary fibrosis and connective tissue disease-related paren- 
chymal lung disease, also portend a worse prognosis. ${ }^{78}$ High-resolution chest computed tomography findings, such as diffuse ground glass opacities and honeycombing, are also associated with worse prognosis. ${ }^{79,80}$

\section{Monitoring Parameters Suggested After Identification of Respiratory Compromise}

Patients with respiratory compromise due to parenchymal lung disease may be monitored continuously for changes in breathing frequency and for decreases in pulse oximetry or oxygen saturation. Because administration of supplemental oxygen may mask the hypoxemic effects of parenchymal lung disease, this type of respiratory compromise is best monitored longitudinally by considering the increases in oxygen supplementation required to maintain adequate oxygenation. Decreases in mental status in the appropriate patient population may reflect the systemic effect of lung inflammation and inadequate oxygen delivery.

\section{Respiratory Compromise Due to Increased Airway Resistance}

\section{Physiological Derangement}

Respiratory compromise due to increased airway resistance adds greatly to the work required for ventilation. Dynamic airway collapse in diseases such as asthma or COPD increases resistance predominantly during exhalation, which decreases tidal volume and $\dot{\mathrm{V}}_{\mathrm{E}}$. Air trapping occurs as the balance between airway resistance and alveolar recoil favors retention of alveolar air at the end of exhalation. Air trapping may in fact worsen as $\dot{V}_{E}$ is increased by tachypnea. The FRC is increased, which impairs the efficiency of the diaphragm and other respiratory musculature and decreases inspiratory capacity. $\dot{\mathrm{V}}_{\mathrm{D}}$ markedly increases, which, along with the decrease in $\dot{V}_{E}$, decreases $\dot{V}_{\mathrm{A}}$ and causes hypoxemia and respiratory acidosis.

The patient initially compensates by shortening the inspiratory time and allowing more time for exhalation. As the condition deteriorates, the patient feels more dyspneic, and $\dot{V}_{\mathrm{E}}$ must be maintained by increasing the breathing frequency, which unfortunately increases the amount of air trapping and $\dot{\mathrm{V}}_{\mathrm{D}} / \dot{\mathrm{V}}_{\mathrm{E}}$. Respiratory failure ensues as the exhausted patient becomes progressively bradypneic.

The hemodynamic effects of intrinsic PEEP from alveolar air trapping commonly complicate respiratory compromise due to increased airway resistance. Positive pressure within the alveoli is transmitted to the intrathoracic vasculature, decreasing venous return and lowering rightventricular stroke volume. The reduction in cardiac output further limits oxygen delivery and can result in catastrophic cardiac failure.

A variant of respiratory compromise due to increased airway resistance occurs if the upper airways are severely obstructed due to edema, laryngospasm, stenosis, or collapse of floppy tracheal segments. The primary problem in this variant of respiratory compromise is the increased work required to sustain ventilation through the narrowed airway. The patient may appear to compensate well, since increased work may maintain ventilation and oxygenation despite high airway resistance. However, the situation deteriorates rapidly if the airway obstruction is sustained or progressive, since a relatively small decrease in airway diameter may raise the airway resistance to levels that are intolerable. Unfortunately, the obstruction itself may limit the options available for airway support if the deterioration is untreated until this point.

\section{Identification of Patients in Respiratory Compromise Due to Increased Airway Resistance}

Patients with diagnoses of COPD, asthma, or other types of airway obstruction who are hospitalized for any reason are at risk for respiratory compromise due to increased airway resistance. The likelihood to develop respiratory compromise is highest if exacerbation of the obstructive lung disease itself is the reason for hospitalization. However, hospitalization of obstructive disease patients for any reason increases the risk for respiratory compromise from increased airway resistance. This type of respiratory compromise can be recognized in the appropriate population by increases above the patient's baseline in the effort required to sustain normal ventilation. Clinical evaluation and proper monitoring of increased ventilatory effort will allow earlier recognition of respiratory compromise due to increased airway resistance before the patient manifests deteriorations in gas exchange.

The severity of a patient's prior exacerbations is an important clue to identify respiratory compromise in patients with an acute asthma episode. Previous ICU admissions and mechanical ventilation episodes were important predictors of respiratory failure in patients hospitalized with asthma, ${ }^{81,82}$ whereas smoking status, duration of asthma, presence of atopy, and types of out-patient inhaled medications were not. ${ }^{81}$ Tachycardia upon presentation ${ }^{81,82}$ and hyperinflation on chest radiography ${ }^{81}$ are associated with subsequent respiratory failure, as is respiratory acidosis in the initial arterial blood gas measurement ${ }^{81,82}$ or decreased oxygen saturation. ${ }^{82}$ Unfortunately, subjective evaluation may be complicated because the ability to perceive dyspnea tends to be lower among asthma patients at high risk of respiratory failure. ${ }^{83}$ The presence of wheezes, rales, prolonged exhalation phases of respiration, and accessory muscle use distinguished patients who required 
hospitalization from those who did not but was not able to predict subsequent respiratory failure. ${ }^{82}$

The patient's previous history is also critical for the identification of respiratory compromise in patients with COPD exacerbation. In the case of COPD, however, the risk of in-hospital respiratory failure depends on the patient's baseline severity of obstruction (eg, $\mathrm{FEV}_{1}{ }^{83,84}$ and the modified Medical Research Council scale for chronic dyspnea ${ }^{84}$ ), in addition to prior episodes of respiratory failure ${ }^{84,85}$ Among findings at presentation, hypoxemia or hypercapnia, ${ }^{85}$ microbiologically confirmed respiratory tract infection, ${ }^{84}$ and treatment with penicillins (vs fluoroquinolones, macrolides, and cephalosporins) ${ }^{84}$ signal a higher rate of subsequent respiratory failure, whereas the presence of cough is associated with lower risk. ${ }^{84}$ Other demographic data, physiological parameters, and routinely measured laboratory results (including the specific type of respiratory pathogen identified) did not distinguish between subsequent treatment failure and success. ${ }^{84}$ On the other hand, the risk of subsequent failure does correlate modestly with increases in laboratory markers of inflammation, such as C-reactive protein, procalcitonin, tumor necrosis factor- $\alpha$, and interleukin- $1 .{ }^{84}$

The clinical presentation of respiratory compromise in patients with acute large-airway obstruction can be acute or subacute. Presenting symptoms include shortness of breath, cough, and wheezing. Rapid deterioration in clinical status can occur due to edema, secretions, or bleeding in the setting of large-airway narrowing. Presentation will depend on the location of the large-airway obstruction, rate of progression of the physiologic obstruction, and underlying cardiopulmonary status. ${ }^{86,87}$ Acute onset of tachypnea, tachycardia, and increased work of breathing should prompt immediate attention to airway management.

\section{Monitoring Parameters Suggested After Identification of Respiratory Compromise}

Patients with respiratory compromise due to increased airway resistance are monitored by frequent heart rate, breathing frequency, and blood pressure measurement. Continuous oximetry and capnometry may be useful, but each has its pitfalls. Pulse oximetry will not detect carbon dioxide retention, the hallmark feature of respiratory compromise due to increased airway resistance; thus, adequate peripheral oxygen saturation levels may give false assurance that ventilation is acceptable. Supplemental oxygen administration increases $\mathrm{P}_{\mathrm{aO}}$ and hemoglobin saturation, but the resulting increases in $\dot{V} / \mathbf{Q}$ mismatch may worsen $\mathrm{CO}_{2}$ retention. Capnography measurement may not be straightforward in patients with obstruction to air flow. End-tidal $\mathrm{P}_{\mathrm{CO}_{2}}$ may be markedly different from arterial $\mathrm{P}_{\mathrm{CO}_{2}}, 88,89$ reflecting alterations in $\dot{\mathrm{V}}_{\mathrm{A}}$, in $\dot{\mathrm{V}}_{\mathrm{D}} / \dot{\mathrm{V}}_{\mathrm{E}}$, or in both.
Clinical scales to quantify dyspnea can be followed over time to help detect respiratory compromise when progression of severity is gradual. Subjective scales, however, while providing the valuable patient perspective, depend on intact cognition for patient response. Acute respiratory compromise due to increased airway resistance is likely to impact cognition adversely, making such scales of questionable value in hypercarbic and/or hypoxemic patients.

\section{Respiratory Compromise Due to Hydrostatic Pulmonary Edema and Due to Right-Ventricular Failure}

\section{Physiological Derangement}

The right side of the heart is responsible for blood flow through the pulmonary capillaries, and cardiac function affects the amount and distribution of flow. Diastolic filling of the ventricle (preload) is determined by fluid status, mean intrathoracic pressure, and compliance of the ventricle. Pulmonary arterial resistance (afterload) is affected by mean intrathoracic pressure, caliber of the pulmonary arteries, hypoxic vasoconstriction, and adrenergic tone.

Although they have similarities, respiratory compromise due to hydrostatic pulmonary edema has a pathophysiology distinct from respiratory compromise due to rightventricular dysfunction. Respiratory compromise due to hydrostatic pulmonary edema is manifested by decreased cardiac output and by the parenchymal effects of pulmonary edema. Pulmonary edema decreases lung compliance, gas exchange, and FRC, which leads to hypoxemia that is similar to respiratory compromise from parenchymal lung disease. Decreased cardiac output adversely affects $\dot{V} / \dot{Q}$ matching and decreases oxygen delivery. Respiratory failure from respiratory compromise due to hydrostatic pulmonary edema may occur as oxygen delivery to the heart, to the muscles of ventilation, and to other vital organs is compromised.

In respiratory compromise due to right-ventricular dysfunction, pulmonary edema is characteristically absent. However, because the right ventricle is much less equipped than the left ventricle to increase its work load, this type of respiratory compromise entails the risk of rapid deterioration and catastrophic cardiac decompensation. The right ventricle initially maintains stroke volume through mechanisms such as increased diastolic filling, but respiratory compromise occurs as the pulmonary arterial resistance increases. The compromise worsens as further increases in diastolic filling overdistend the right ventricle and decrease the stroke volume. Respiratory compromise deteriorates into respiratory failure as the cardiac output drops and blood flow to vital organs is critically reduced. The muscle of the right ventricle itself is especially compromised because its demand is so extreme and its internal pressure is 
high enough to limit coronary blood flow. Patients with chronic right-ventricular strain (eg, those with pulmonary arterial hypertension) are capable of a greater degree of right-ventricular work than patients with more abrupt problems, such as acute pulmonary embolism. In both patient groups, however, right-ventricular failure is the principal danger.

Respiratory compromise due to right-ventricular dysfunction may be complicated by impaired V/Q ratios. The most common gas exchange problem is increased perfusion to underventilated lung regions that results from redistribution of pulmonary blood flow. Although the low $\dot{V} / \mathrm{Q}$ may cause hypoxemia, that particular manifestation of right-ventricular dysfunction is particularly responsive to supplemental oxygen. The responsiveness to oxygen is another instance in which exclusive attention to blood oxygenation may create a false sense of security in the care of some patients with respiratory compromise.

\section{Identification of Patients in Respiratory Compromise From Hydrostatic Pulmonary Edema}

Patients with pulmonary edema are diagnosed on the basis of clinical, radiographic, and laboratory findings. Respiratory compromise from hydrostatic pulmonary edema is identified when oxygen saturation decreases, when $\mathrm{F}_{\mathrm{IO}_{2}}$ requirements increase, or when the breathing frequency and overall appearance suggest increased effort of breathing. These findings reflect extravascular lung water, which worsens gas exchange and increases lung elastance.

Respiratory compromise in patients with acute hydrostatic (cardiogenic) pulmonary edema may be identified by findings associated with increased mortality risk. A high proportion of in-hospital mortality with acute cardiogenic pulmonary edema occurs on the first hospital day, ${ }^{90}$ making early prognostic assessment important. Acute myocardial infarction as the precipitant for pulmonary edema is associated with increased in-hospital mortality. ${ }^{91,92}$ Age, hypotension, recurrence of acute pulmonary edema, and need for inotropic therapy were the main independent predictors of hospital mortality. ${ }^{92}$ In patients without acute myocardial infarction, the presence of atrial fibrillation significantly increased in-hospital mortality. ${ }^{93}$ A prognostic scoring system, the pulmonary edema prognostic score, has been described with predictors of in-hospital mortality: acute myocardial infarction, hypotension, tachycardia, and leukocytosis. ${ }^{94}$

\section{Monitoring Parameters Suggested After Identification of Respiratory Compromise}

The goal of monitoring during respiratory compromise from hydrostatic pulmonary edema, as in other variants of respiratory compromise, is to determine the trajectory of the disease. Straightforward methods such as breathing frequency and oxygen saturation (linked with $\mathrm{F}_{\mathrm{IO}_{2}}$ requirements) are best considered longitudinally to detect escalating severity. Surveillance of ventilatory patterns, the effort required to sustain breathing, and estimation of extravascular lung water currently require frequent subjective evaluations. However, technological developments may enhance the ability to monitor these parameters continuously and detect deterioration in a timely fashion.

\section{Identification of Patients in Respiratory Compromise Due to Right-Ventricular Dysfunction}

Acute pulmonary embolism, pulmonary arterial hypertension, and other causes of right-ventricular strain require specific diagnostic techniques. Identification of respiratory compromise due to right-ventricular dysfunction depends on the estimation of both the severity of the effects on the right ventricle and on the risk of worsening. For acute pulmonary embolism, the combination of severity and risk is estimated with clinically validated scores, such as the pulmonary embolism severity index. ${ }^{54,55,95}$ Respiratory compromise in patients with acute pulmonary embolism may be identified by findings associated with increased mortality risk, such as high clinical severity indices (mortality risk $\sim 20 \%)^{54,55,95,96}$; elevated markers of cardiac strain, such as troponin or brain natriuretic peptide (mortality relative risk $\geq 8)^{94-98}$; electrocardiogram evidence of right-ventricular ischemia (mortality odds ratio $\geq 2$ ) ) $^{100-103}$; or evidence of severe right-ventricular dysfunction documented by computed tomography (contrast reflux, mortality odds ratio $\geq 3$ ) ${ }^{103}$ or echocardiogram (mortality odds ratio $\geq 2) .{ }^{105,106}$

\section{Monitoring Parameters Suggested After Identification of Respiratory Compromise}

Continuous monitoring of breathing frequency and oxygen saturation may be helpful, although it is noteworthy that hypoxemia from pulmonary vascular diseases may respond well to supplemental oxygen therapy, even as hemodynamics deteriorate. Progressive right-ventricular failure constitutes the principal danger, ${ }^{107}$ so echocardiography and serologic tests of cardiac strain and damage should be checked periodically. Continuous electrocardiogram monitoring may detect new T-wave inversions in the precordial leads, an ominous sign of right-ventricular worsening. Capnography may detect changes in dead space ventilation, and plethysmography may detect changes in pulse pressure variation, although the clinical importance of those findings in the acute setting is unknown. 


\section{Manifestations Common to Different Types of Respiratory Compromise}

In addition to the relatively specific patterns of deterioration observed for the various etiologies and mechanisms of respiratory compromise, all types of severe respiratory compromise may manifest similar effects on non-respiratory systems. Hypoxemia adversely affects the central nervous system, so confusion, delirium, obtundation, and other changes in level of consciousness and behavior may occur as hypoxemia worsens. Severe hypoxemia can impair the function of many systemic organs and worsen multiple organ dysfunction syndromes. Hypoxemia and severe acidosis impair cardiac function, alter vascular tone, and can lead to hemodynamic collapse. Dyspnea and muscle loading may encourage hormonal stress responses and adrenergic stimulation, further jeopardizing vulnerable organs.

\section{Summary and Recommendations}

Respiratory compromise is a deterioration in respiratory function in which there is a high likelihood of decompensation into respiratory failure or death but for which timely specific interventions (enhanced monitoring or therapies) might prevent or mitigate decompensation. Importantly, specific interventions (enhanced monitoring or therapies) might prevent or mitigate this decompensation. The high incidence of respiratory failure and death among hospitalized patients suggests that an opportunity exists to intervene at earlier stages in many patients. Although respiratory failure may complicate a variety of different conditions, we have described general categories of respiratory compromise, each of which has its own pattern of physiological deterioration. Classifying an acutely ill respiratory patient into one or more of these categories may help in selecting the screening and monitoring strategies that are most appropriate for the patient's particular pathophysiology. Although specific diagnostic and therapeutic interventions must be individualized, standardized screening and monitoring practices for patients with similar mechanisms of deterioration may enhance the ability to predict respiratory failure early and prevent its occurrence.

\section{ACKNOWLEDGMENTS}

We thank Phillip Porte, whose diligent work fostered the creation of this monograph and the formation of the Respiratory Compromise Institute to address the unmet needs identified herein.

Complete author list: Timothy A Morris MD, University of California, San Diego, California (meeting chair); Lydia Chang MD, University of North Carolina, Chapel Hill, North Carolina (representing the American Thoracic Society); Dennis E Doherty MD, University of Kentucky School of Medicine, Lexington, Kentucky (representing the National Association for Medical Direction of Respiratory Care); Ernest Eugene Gantt RRT (representing the American Association for Respiratory Care); Peter
C Gay MD, Mayo Clinic, Rochester, Minnesota; Sandra K Hanneman $\mathrm{PhD}$ RN, University of Texas Health Science Center, Houston, Texas (representing the American Association of Critical-Care Nurses); Dean R Hess PhD RRT FAARC, Massachusetts General Hospital, Boston, Massachusetts; Nicolas S Hill MD, Tufts University School of Medicine, Boston, Massachusetts; Keith D Lamb RRT-ACCS, Iowa Methodist Medical Center, Des Moines, Iowa; James P Lamberti MD, Inova Fairfax Hospital, Annandale, Virginia; Neil R MacIntyre MD FAARC, Duke University School of Medicine, Durham, North Carolina; Peter S Marshall MD MPH, Yale University School of Medicine, New Haven, Connecticut; James AL Mathers MD, Pulmonary Associates of Richmond, Richmond, Virginia; Peter E Morris MD, University of Kentucky School of Medicine, Lexington, Virginia; Maureen A Seckel APRN, Christiana Care Health Services, Wilmington, Delaware; Todd L Slesinger MD, Aventura Hospital and Medical Center, Aventura, Florida (representing the American College of Emergency Physicians); Jeffery S Vender MD, NorthShore University Health System, Evanston, Illinois (representing the Society for Critical Care Medicine); and Michael Wong (representing the Physician-Patient Alliance for Health and Safety).

\section{REFERENCES}

1. Broniatowski M, Grundfest-Broniatowski S, Hadley AJ, Shah NS, Barbu AM, Phillipbar SA, et al. Improvement of respiratory compromise through abductor reinnervation and pacing in a patient with bilateral vocal fold impairment. Laryngoscope 2010; 120(1):76-83.

2. Bloom CI, Wilson GE. Rounded atelectasis and respiratory compromise secondary to pergolide use. Respirology 2009;14(6):906907.

3. Andersen LW, Berg KM, Chase M, Cocchi MN, Massaro J, Donnino MW, et al. Acute respiratory compromise on inpatient wards in the United States: Incidence, outcomes, and factors associated with in-hospital mortality. Resuscitation 2016;105:123-129.

4. Lee JS, Giesler DL, Gellad WF, Fine MJ. Antibiotic therapy for adults hospitalized with community-acquired pneumonia: a systematic review. JAMA 2016;315(6):593-602.

5. Keenan SP, Sinuff T, Cook DJ, Hill NS. Which patients with acute exacerbation of chronic obstructive pulmonary disease benefit from noninvasive positive-pressure ventilation? A systematic review of the literature. Ann Intern Med 2003;138(11):861-870.

6. Rothberg MB, Pekow PS, Priya A, Lindenauer PK. Variation in diagnostic coding of patients with pneumonia and its association with hospital risk-standardized mortality rates: a cross-sectional analysis. Ann Intern Med 2014;160(6):380-388.

7. Heslin MJ, Taylor B, Hawn MT, Davies JE, Heslin RT, Mims AH, et al. A $100 \%$ departmental mortality review improves observedto-expected mortality ratios and University HealthSystem Consortium rankings. J Am Coll Surg 2014;218(4):554-562.

8. Ruhnke GW, Coca Perraillon M, Cutler DM. Mortality reduction among pneumonia patients still substantial despite the impact of coding changes. Am J Med 2013;126(3):266-269.

9. Lindenauer PK, Lagu T, Shieh MS, Pekow PS, Rothberg MB. Association of diagnostic coding with trends in hospitalizations and mortality of patients with pneumonia, 2003-2009. JAMA 2012; 307(13):1405-1413.

10. Alvarez MP, Samayoa-Mendez AX, Naglak MC, Yuschak JV, Murayama KM. Risk factors for postoperative unplanned intubation: analysis of a national database. Am Surg 2015;81(8):820-825.

11. Hall MJ, Levant S, DeFrances CJ. Trends in inpatient hospital deaths: National Hospital Discharge Survey, 2000-2010. NCHS data brief 2013;118:1-8.

12. Djärv T, Castrén M, Mårtenson L, Kurland L. Decreased general condition in the emergency department: high in-hospital mortality 


\section{Respiratory Compromise Paradigm for the Care of Vulnerable Patients}

and a broad range of discharge diagnoses. Eur J Emerg Med 2015; 22(4):241-246.

13. Le Guen M, Tobin A. Epidemiology of in-hospital mortality in acute patients admitted to a tertiary level hospital. Intern Med J 2016;46(4):457-464.

14. Janisch T, Wendt J, Hoffmann R, Ortlepp JR. Expected and observed mortality in critically ill patients receiving initial antibiotic therapy. Wiener klinische Wochenschrift 2012;124(21):775-781.

15. Aliberti S, Bellelli G, Belotti M, Morandi A, Messinesi G, Annoni G, Pesci A. Delirium symptoms during hospitalization predict longterm mortality in patients with severe pneumonia. Aging Clin Exp Res 2015;27(4):523-531.

16. Lanspa MJ, Jones BE, Brown SM, Dean NC. Mortality, morbidity, and disease severity of patients with aspiration pneumonia. J Hosp Med 2013;8(2):83-90.

17. Corrales-Medina VF, Musher DM, Wells GA, Chirinos JA, Chen L, Fine MJ. Cardiac complications in patients with community-acquired pneumonia: incidence, timing, risk factors, and association with short-term mortality. Circulation 2012;125(6):773-781.

18. Rello J, Luján M, Gallego M, Vallés J, Belmonte Y, Fontanals D, et al. Why mortality is increased in health-care-associated pneumonia: lessons from pneumococcal bacteremic pneumonia. Chest 2010; 137(5):1138-1144.

19. Lee N, Lui GC, Wong KT, Li TC, Tse EC, Chan JY, et al. High morbidity and mortality in adults hospitalized for respiratory syncytial virus infections. Clin Infect Dis 2013;57(8):1069-1077.

20. Mokart D, Azoulay E, Schnell D, Bourmaud A, Kouatchet A, Pène $\mathrm{F}$, et al. Acute respiratory failure in neutropenic patients is associated with a high post-ICU mortality. Minerva Anestesiol 2013; 79(10):1156-1163.

21. Villa F, Coppadoro A, Bellani G, Foti G, Fumagalli R, Pesenti A. Etiology of respiratory failure is related to mortality in critically ill patients affected by a hematological malignancy: a retrospective study. Minerva Anestesiol 2010;76(1):7-12.

22. Schmickl CN, Biehl M, Wilson GA, Gajic O. Comparison of hospital mortality and long-term survival in patients with acute lung injury/ARDS vs cardiogenic pulmonary edema. Chest 2015;147(3): 618-625.

23. Ai-Ping C, Lee KH, Lim TK. In-hospital and 5-year mortality of patients treated in the ICU for acute exacerbation of COPD: a retrospective study. Chest 2005;128(2):518-524.

24. Bustamante-Fermosel A, De Miguel-Yanes JM, Duffort-Falcó M, Muñoz J. Mortality-related factors after hospitalization for acute exacerbation of chronic obstructive pulmonary disease: the burden of clinical features. Am J Emerg Med 2007;25(5):515-522.

25. Terzano C, Conti V, Di Stefano F, Petroianni A, Ceccarelli D, Graziani E, et al. Comorbidity, hospitalization, and mortality in COPD: results from a longitudinal study. Lung 2010;188(4):321329.

26. Braunstein JB, Anderson GF, Gerstenblith G, Weller W, Niefeld M, Herbert R, Wu AW. Noncardiac comorbidity increases preventable hospitalizations and mortality among Medicare beneficiaries with chronic heart failure. J Am Coll Cardiol 2003;42(7): 1226-1233.

27. Task Force of the American College of Critical Care Medicine, Society of Critical Care Medicine. Guidelines for intensive care unit admission, discharge, and triage. Crit Care Med 1999;27(3): 633-638.

28. Simchen E, Sprung CL, Galai N, Zitser-Gurevich Y, Bar-Lavi Y, Levi L, et al. Survival of critically ill patients hospitalized in and out of intensive care. Crit Care Med 2007;35(2):449-457.

29. Mokart D, Lambert J, Schnell D, Fouché L, Rabbat A, Kouatchet A, et al. Delayed intensive care unit admission is associated with increased mortality in patients with cancer with acute respiratory failure. Leuk Lymphoma 2013;54(8):1724-1729.

30. Castro AA, Calil SR, Freitas SA, Oliveira AB, Porto EF. Chest physiotherapy effectiveness to reduce hospitalization and mechanical ventilation length of stay, pulmonary infection rate and mortality in ICU patients. Respir Med 2013;107(1):68-74.

31. Barfod C, Lauritzen MM, Danker JK, Sölétormos G, Forberg JL, Berlac PA, et al. Abnormal vital signs are strong predictors for intensive care unit admission and in-hospital mortality in adults triaged in the emergency department: a prospective cohort study. Scand J Trauma Resusc Emerg Med 2012;20:28.

32. Myint PK, Trepte NJ, Parker RA, Sultanzadeh SJ, Patel J, Mallinson R, Potter JF. Vital signs as determinants of immediate and longer term mortality outcome of patients admitted from nursing homes. Aging clinical and experimental research 2011;23(4):309315.

33. Francia E, Torres O, Laiz A, Ruiz D, Gich I, Casademont J. Ability of physiological parameters versus clinical categories to predict mortality on admission to an internal medicine ward. Eur J Int Med 2009;20(6):636-639.

34. Goodacre S, Wilson R, Shephard N, Nicholl J. Derivation and validation of a risk adjustment model for predicting seven day mortality in emergency medical admissions: mixed prospective and retrospective cohort study. BMJ 2012;344:e2904.

35. Cei M, Bartolomei C, Mumoli N. In-hospital mortality and morbidity of elderly medical patients can be predicted at admission by the Modified Early Warning Score: a prospective study. Int J Clin Pract 2009;63(4):591-595.

36. Burch VC, Tarr G, Morroni C. Modified early warning score predicts the need for hospital admission and inhospital mortality. Emerg Med J 2008;25(10):674-678.

37. Paterson R, MacLeod DC, Thetford D, Beattie A, Graham C, Lam $\mathrm{S}$, et al. Prediction of in-hospital mortality and length of stay using an early warning scoring system: clinical audit. Clin Med 2006; 6(3):281-284.

38. Martins M, Blais R. Evaluation of comorbidity indices for inpatient mortality prediction models. J Clin Epidemiol 2006;59(7):665-669.

39. Goodacre S, Turner J, Nicholl J. Prediction of mortality among emergency medical admissions. Emerg Med J 2006;23(5):372-375.

40. Doherty SR, Hore CT, Curran SW. Inpatient mortality as related to triage category in three New South Wales regional base hospitals. Emerg Med 2003;15(4):334-340.

41. Miles LF, Bailey M, Young P, Pilcher DV. Differences in mortality based on worsening ratio of partial pressure of oxygen to fraction of inspired oxygen corrected for immune system status and respiratory support. Crit Care Resusc 2012;14(1):25-32.

42. Luque S, Gea J, Saballs P, Ferrández O, Berenguer N, Grau S. Prospective comparison of severity scores for predicting mortality in community-acquired pneumonia. Rev Esp Quimioter 2012;25(2): 147-154.

43. Chang CL, Mills GD, Karalus NC, Jennings LC, Laing R, Murdoch $\mathrm{DR}$, et al. Biomarkers of cardiac dysfunction and mortality from community-acquired pneumonia in adults. PLoS One 2013;8(5): e62612.

44. Ma HM, Tang WH, Woo J. Predictors of in-hospital mortality of older patients admitted for community-acquired pneumonia. Age Ageing 2011;40(6):736-741.

45. García-Vázquez E, Soto S, Gómez J, Herrero JA. Simple criteria to assess mortality in patients with community-acquired pneumonia. Med Clin 2008;131(6):201-204.

46. Marrie TJ, Wu L. Factors influencing in-hospital mortality in community-acquired pneumonia: a prospective study of patients not initially admitted to the ICU. Chest 2005;127(4):1260-1270. 


\section{Respiratory Compromise Paradigm for the Care of Vulnerable Patients}

47. Arozullah AM, Parada J, Bennett CL, Deloria-Knoll M, Chmiel JS, Phan L, Yarnold PR. A rapid staging system for predicting mortality from HIV-associated community-acquired pneumonia. Chest 2003;123(4):1151-1160.

48. Houston MS, Silverstein MD, Suman VJ. Risk factors for 30-day mortality in elderly patients with lower respiratory tract infection: community-based study. Arch Intern Med 1997;157(19): 2190-2195.

49. Mandell LA, Wunderink RG, Anzueto A, Bartlett JG, Campbell GD, Dean NC, et al. Infectious Diseases Society of America/American Thoracic Society consensus guidelines on the management of community-acquired pneumonia in adults. Clin Infect Dis 2007; 44(Suppl 2):S27-S72.

50. Messer B, Griffiths J, Baudouin SV. The prognostic variables predictive of mortality in patients with an exacerbation of COPD admitted to the ICU: an integrative review. QJM 2012;105(2):115126.

51. Chang CL, Sullivan GD, Karalus NC, Mills GD, McLachlan JD, Hancox RJ. Predicting early mortality in acute exacerbation of chronic obstructive pulmonary disease using the CURB65 score. Respirology 2011;16(1):146-151.

52. Aburto M, Esteban C, Moraza FJ, Aguirre U, Egurrola M, Capelastegui A. COPD exacerbation: mortality prognosis factors in a respiratory care unit. Arch Bronconeumol 2011;47(2):79-84.

53. Wildman MJ, Sanderson C, Groves J, Reeves BC, Ayres J, Harrison $\mathrm{D}$, et al. Predicting mortality for patients with exacerbations of COPD and asthma in the COPD and Asthma Outcome Study (CAOS). QJM 2009;102(6):389-399.

54. Donzé J, Le Gal G, Fine MJ, Roy PM, Sanchez O, Verschuren F, et al. Prospective validation of the pulmonary embolism severity index: a clinical prognostic model for pulmonary embolism. Thromb Haemost 2008;100(5):943-948.

55. Jiménez D, Aujesky D, Moores L, Gómez V, Lobo JL, Uresandi F, et al. Simplification of the pulmonary embolism severity index for prognostication in patients with acute symptomatic pulmonary embolism. Arch Intern Med 2010;170(15):1383-1389.

56. Fartoukh M, Khoshnood B, Parrot A, Khalil A, Carette MF, Stoclin A, et al. Early prediction of in-hospital mortality of patients with hemoptysis: an approach to defining severe hemoptysis. Respiration 2012;83(2):106-114.

57. Berwick DM, Calkins DR, McCannon CJ, Hackbarth AD. The 100,000 lives campaign: setting a goal and a deadline for improving health care quality. JAMA 2006;295(3):324-327.

58. Maharaj R, Raffaele I, Wendon J. Rapid response systems: a systematic review and meta-analysis. Crit Care 2015;19:254.

59. Chan PS, Khalid A, Longmore LS, Berg RA, Kosiborod M, Spertus JA. Hospital-wide code rates and mortality before and after implementation of a rapid response team. JAMA 2008;300(21):25062513.

60. Butcher BW, Vittinghoff E, Maselli J, Auerbach AD. Impact of proactive rounding by a rapid response team on patient outcomes at an academic medical center. J Hosp Med 2013;8(1):7-12.

61. Manthous CA, Mokhlesi B. Avoiding management errors in patients with obesity hypoventilation syndrome. Ann Am Thorac Soc 2016;13(1):109-114.

62. Marik PE, Desai H. Characteristics of patients with the "malignant obesity hypoventilation syndrome" admitted to an ICU. J Intensive Care Med 2013;28(2):124-130.

63. Bülbül Y, Ayik S, Ozlu T, Orem A. Frequency and predictors of obesity hypoventilation in hospitalized patients at a tertiary health care institution. Ann Thorac Med 2014;9(2):87-91.

64. van der Maarel-Wierink CD, Vanobbergen JN, Bronkhorst EM, Schols JM, de Baat C. Meta-analysis of dysphagia and aspiration pneumonia in frail elders. J Dental Res 2011;90(12):1398-1404.
65. Manabe T, Teramoto S, Tamiya N, Okochi J, Hizawa N. Risk factors for aspiration pneumonia in older adults. PLoS One 2015; 10(10):e0140060.

66. Hu X, Yi ES, Ryu JH. Diffuse aspiration bronchiolitis: analysis of 20 consecutive patients. J Bras Pneumol 2015;41(2):161-166.

67. Marik PE. Pulmonary aspiration syndromes. Curr Opin Pulm Med 2011;17(3):148-154.

68. Lanspa MJ, Peyrani P, Wiemken T, Wilson EL, Ramirez JA, Dean NC. Characteristics associated with clinician diagnosis of aspiration pneumonia: a descriptive study of afflicted patients and their outcomes. J Hosp Med 2015;10(2):90-96.

69. Lee A, Festic E, Park PK, Raghavendran K, Dabbagh O, Adesanya A, et al. Characteristics and outcomes of patients hospitalized following pulmonary aspiration. Chest 2014;146(4):899-907.

70. Echevarria IM, Schwoebel A. Development of an intervention model for the prevention of aspiration pneumonia in high-risk patients on a medical-surgical unit. Medsurg Nurs 2012;21(5):303-308.

71. Trillo-Alvarez C, Cartin-Ceba R, Kor DJ, Kojicic M, Kashyap R, Thakur S, et al. Acute lung injury prediction score: derivation and validation in a population-based sample. Eur Respir J 2011;37(3): 604-609.

72. Huie TJ, Olson AL, Cosgrove GP, Janssen WJ, Lara AR, Lynch DA, et al. A detailed evaluation of acute respiratory decline in patients with fibrotic lung disease: aetiology and outcomes. Respirology 2010;15(6):909-917.

73. Luppi F, Cerri S, Taddei S, Ferrara G, Cottin V. Acute exacerbation of idiopathic pulmonary fibrosis: a clinical review. Intern Emerg Med 2015;10(4):401-411.

74. Disayabutr S, Calfee CS, Collard HR, Wolters PJ. Interstitial lung diseases in the hospitalized patient. BMC Med 2015;13:245.

75. Moua T, Westerly BD, Dulohery MM, Daniels CE, Ryu JH, Lim KG. Patients with fibrotic interstitial lung disease hospitalized for acute respiratory worsening: a large cohort analysis. Chest 2016; 149(5):1205-1214.

76. Hadley R, Hyzy R. Critically ill patients with interstitial lung disease. Clin Chest Med 2015;36(3):497-510.

77. Hutchinson JP, Fogarty AW, McKeever TM, Hubbard RB. Inhospital mortality after surgical lung biopsy for interstitial lung disease in the United States: 2000 to 2011. Am J Respir Crit Care Med 2016;193(10):1161-1167.

78. Park IN, Kim DS, Shim TS, Lim CM, Lee SD, Koh Y, et al. Acute exacerbation of interstitial pneumonia other than idiopathic pulmonary fibrosis. Chest 2007;132(1):214-220.

79. Akira M, Kozuka T, Yamamoto S, Sakatani M. Computed tomography findings in acute exacerbation of idiopathic pulmonary fibrosis. Am J Respir Crit Care Med 2008;178(4):372-378.

80. Fujimoto K, Taniguchi H, Johkoh T, Kondoh Y, Ichikado K, Sumikawa $\mathrm{H}$, et al. Acute exacerbation of idiopathic pulmonary fibrosis: high-resolution CT scores predict mortality. Eur Radiol 2012;22(1): 83-92.

81. Turner MO, Noertjojo K, Vedal S, Bai T, Crump S, Fitzgerald JM. Risk factors for near-fatal asthma: a case-control study in hospitalized patients with asthma. Am J Respir Crit Care Med 1998;157(6 Pt 1):1804-1809.

82. Dankner R, Olmer L, Ziv A, Bentancur AG. A simplified severity score for acute asthma exacerbation. J Asthma 2013;50(8):871-876.

83. Magadle R, Berar-Yanay N, Weiner P. The risk of hospitalization and near-fatal and fatal asthma in relation to the perception of dyspnea. Chest 2002;121(2):329-333.

84. Crisafulli E, Torres A, Huerta A, Guerrero M, Gabarrús A, Gimeno A, et al. Predicting in-hospital treatment failure ( $\leq 7$ days) in patients with COPD exacerbation using antibiotics and systemic steroids. COPD 2016;13(1):82-92. 


\section{Respiratory Compromise Paradigm for the Care of Vulnerable Patients}

85. Matkovic Z, Huerta A, Soler N, Domingo R, Gabarrus A, Torres A, Miravitlles M. Predictors of adverse outcome in patients hospitalised for exacerbation of chronic obstructive pulmonary disease. Respiration 2012;84(1):17-26.

86. Ernst A, Feller-Kopman D, Becker HD, Mehta AC. Central airway obstruction. Am J Respir Crit Care Med 2004;169(12):1278-1297.

87. Barros Casas D, Fernández-Bussy S, Folch E, Flandes Aldeyturriaga J, Majid A. Non-malignant central airway obstruction. Arch Bronconeumol 2014;50(8):345-354.

88. Cinar O, Acar YA, Arziman I, Kilic E, Eyi YE, Ocal R. Can mainstream end-tidal carbon dioxide measurement accurately predict the arterial carbon dioxide level of patients with acute dyspnea in ED. Am J Emerg Med 2012;30(2):358-361.

89. Doğan NÖ, Şener A, Günaydin GP, İcme F, Çelik GK, Kavakli HŞ, Temrel TA. The accuracy of mainstream end-tidal carbon dioxide levels to predict the severity of chronic obstructive pulmonary disease exacerbations presented to the ED. Am J Emerg Med 2014; 32(5):408-411.

90. Chioncel O, Ambrosy AP, Bubenek S, Filipescu D, Vinereanu D, Petris A, et al. Epidemiology, pathophysiology, and in-hospital management of pulmonary edema: data from the Romanian Acute Heart Failure Syndromes registry. J Cardiovasc Med 2016;17(2):92-104.

91. Roguin A, Behar D, Ben Ami H, Reisner SA, Edelstein S, Linn S, Edoute Y. Long-term prognosis of acute pulmonary oedema: an ominous outcome. Eur J Heart Fail 2000;2(2):137-144.

92. Figueras J, Bañeras J, Peña-Gil C, Barrabés JA, Rodriguez Palomares J, Garcia Dorado D. Hospital and 4-year mortality predictors in patients with acute pulmonary edema with and without coronary artery disease. J Am Heart Assoc 2016;5(2):e002581.

93. Koraćević G, Janković-Tomašević R, Dimitrijević E, Stojković A, Petrović S, Pavlović M, et al. Atrial fibrillation doubled in-hospital mortality in 1379 acute cardiogenic pulmonary edema patients. Facta Universitatis Ser Med Biol 2016;17(1):33-35.

94. Fiutowski M, Waszyrowski T, Krzemińska-Pakula M, Kasprzak JD. Pulmonary edema prognostic score predicts in-hospital mortality risk in patients with acute cardiogenic pulmonary edema. Heart Lung 2008;37(1):46-53.

95. Jiménez D, Aujesky D, Yusen RD. Risk stratification of normotensive patients with acute symptomatic pulmonary embolism. Br J Haematol 2010;151(5):415-424.

96. Jiménez D, Aujesky D, Moores L, Gómez V, Martí D, Briongos S, et al. Combinations of prognostic tools for identification of highrisk normotensive patients with acute symptomatic pulmonary embolism. Thorax 2011;66(1):75-81.
97. Sanchez O, Trinquart L, Colombet I, Durieux P, Huisman MV, Chatellier G, Meyer G. Prognostic value of right ventricular dysfunction in patients with haemodynamically stable pulmonary embolism: a systematic review. Eur Heart J 2008;29(12):1569-1577.

98. Konstantinides S, Geibel A, Olschewski M, Kasper W, Hruska N, Jäckle S, Binder L. Importance of cardiac troponins I and T in risk stratification of patients with acute pulmonary embolism. Circulation 2002;106(10):1263-1268.

99. Jiménez D, Uresandi F, Otero R, Lobo JL, Monreal M, Martí D, et al. Troponin-based risk stratification of patients with acute nonmassive pulmonary embolism: systematic review and metaanalysis. Chest 2009;136(4):974-982.

100. Kukla P, Długopolski R, Krupa E, Furtak R, Mirek-Bryniarska E, Jastrzębski M, et al. The prognostic value of ST-segment elevation in the lead aVR in patients with acute pulmonary embolism. Kardiol Pol 2011;69(7):649-654.

101. Kukla P, Długopolski R, Krupa E, Furtak R, Wrabec K, Szełemej $\mathrm{R}$, et al. The value of ECG parameters in estimating myocardial injury and establishing prognosis in patients with acute pulmonary embolism. Kardiol Pol 2011;69(9):933-938.

102. Kukla P, McIntyre WF, Fijorek K, Długopolski R, Mirek-Bryniarska $\mathrm{E}$, Bryniarski KL, et al. T-wave inversion in patients with acute pulmonary embolism: prognostic value. Heart Lung 2015;44(1):68-71.

103. Kukla P, McIntyre WF, Fijorek K, Mirek-Bryniarska E, Bryniarski L, Krupa E, et al. Electrocardiographic abnormalities in patients with acute pulmonary embolism complicated by cardiogenic shock. Am J Emerg Med 2014;32(6):507-510.

104. Bach AG, Nansalmaa B, Kranz J, Taute BM, Wienke A, Schramm D, Surov A. CT pulmonary angiography findings that predict 30day mortality in patients with acute pulmonary embolism. Eur J Radiol 2015;84(2):332-337.

105. Cho JH, Kutti Sridharan G, Kim SH, Kaw R, Abburi T, Irfan A, Kocheril AG. Right ventricular dysfunction as an echocardiographic prognostic factor in hemodynamically stable patients with acute pulmonary embolism: a meta-analysis. BMC Cardiovasc Disord 2014;14:64.

106. Ribeiro A, Lindmarker P, Juhlin-Dannfelt A, Johnsson H, Jorfeldt L. Echocardiography Doppler in pulmonary embolism: right ventricular dysfunction as a predictor of mortality rate. Am Heart $\mathbf{J}$ 1997;134(3):479-487.

107. Kasper W, Konstantinides S, Geibel A, Olschewski M, Heinrich F, Grosser KD, et al. Management strategies and determinants of outcome in acute major pulmonary embolism: results of a multicenter registry. J Am Coll Cardiol 1997;30(5):1165-1171. 